\author{
Marquette University \\ e-Publications@Marquette
}

School of Dentistry Faculty Research and

Publications

Dentistry, School of

6-2015

\title{
Congenital Adrenal Hyperplasia: A Case Report with Premature Teeth Exfoliation and Bone Resorption
}

\author{
Matina V. Angelopoulou \\ Marquette University, matina.angelopoulou@marquette.edu \\ Elias D. Kontogiorgos \\ Texas A\&M University \\ Dimitris E. Emmanouil \\ University of Athens
}

Follow this and additional works at: https://epublications.marquette.edu/dentistry_fac

Part of the Dentistry Commons

\section{Recommended Citation}

Angelopoulou, Matina V.; Kontogiorgos, Elias D.; and Emmanouil, Dimitris E., "Congenital Adrenal Hyperplasia: A Case Report with Premature Teeth Exfoliation and Bone Resorption" (2015). School of Dentistry Faculty Research and Publications. 167.

https://epublications.marquette.edu/dentistry_fac/167 


\title{
Congenital Adrenal Hyperplasia: A Case Report With Premature Teeth Exfoliation and Bone Resorption
}

\author{
Matina V. Angelopoulou \\ Division of Pediatric Dentistry, Marquette University School of Dentistry, \\ Milwaukee, Wisconsin \\ Elias Kontogiorgos \\ Department of Restorative Sciences, Texas A\&M Baylor College of \\ Dentistry, Dallas, Texas \\ Dimitris Emmanouil \\ Department of Paediatric Dentistry, Dental School, University of Athens, Greece
}

\begin{abstract}
Congenital adrenal hyperplasia $(\mathrm{CAH})$ is an inherited autosomal recessive disorder characterized by insufficient production of cortisol. The aim of this case report was to present a child with $\mathrm{CAH}$, premature exfoliation of primary teeth and accelerated eruption of his permanent teeth related to bone resorption. A 4.5-year-old Caucasian boy with CAH and long-term administration of glucocorticoids was referred for dental restoration. Clinical examination revealed primary molars with worn stainless steel crowns, severe attrition of the upper canines, and absence of the upper incisors. Before the completion of treatment, abnormal mobility of the first upper primary molars and the lower incisors was detected, and a few days later the teeth exfoliated prematurely. Histologic examination revealed normal tooth structure. Alkaline phosphatase and blood cells values were normal. Eruption of the permanent dentition was also accelerated. Tooth mobility was noticed in the permanent teeth as soon as they erupted, along with bone destruction. Examination revealed an elevated level of receptor activator of nuclear factor- $\kappa \mathrm{B}$ ligand and lower-than-normal osteoprotegerin and vitamin D levels. The patient was treated with vitamin D supplements, and his teeth have been stable ever since. CAH is a serious chronic disorder appearing in children with accelerated dental development and possibly premature loss of primary teeth.
\end{abstract}

Congenital adrenal hyperplasia ( $\mathrm{CAH})$ is an inherited disorder that leads to insufficient production of cortisol caused by abnormality in 1 of the 5 enzymes that are 
necessary for its biosynthesis. $\underline{1}-\underline{3}$ Glucocorticoid and mineralocorticoid administration is the therapy of choice. 4 However, chronic administration of corticosteroids may cause growth retardation, drug-induced osteoporosis, glucose intolerance, and infection susceptibility. $\underline{5}$

Increased bone resorption in patients with $\mathrm{CAH}$ has been noted in the past and has been related to alterations in receptor activator of nuclear factor- $\kappa \mathrm{B}$ ligand (RANKL) and osteoprotegerin (OPG). 6 This effect might be caused by the long-term administration of corticosteroids or the excessive secretion of adrenocorticotropic hormone. ${ }^{7}$ Also, bone resorption has been related with loss of teeth in patients with osteolytic diseases. $\underline{8}$

In addition, adrenal hyperactivation has been found to increase infection susceptibility 9 and increase the risk for development of periodontal disease. 10 Periodontal disease is related to loss of teeth. $\underline{11}$

Accelerated tooth eruption has been reported in patients with CAH. $\underline{12}-\underline{15}$ Long-term therapy with glucocorticoids $\underline{15} \underline{16}$ and excessive hormonal secretion $\underline{13}, \underline{14}$ have been associated with the acceleration of dental development. Recently, bone resorption has been found to be correlated with accelerated eruption of teeth in mice. $\underline{17}$

Premature exfoliation of teeth has not been reported in patients with CAH. However, susceptibility to periodontal disease and bone resorption can be the cause for primary exfoliation of primary teeth and accelerated eruption of its successors.

The aim of this case report is to present a child with CAH with premature exfoliation of primary teeth and accelerated eruption of his permanent teeth caused by bone resorption.

\section{Case Report}

A 4.5-year-old white boy was referred in June 2010 to the postgraduate clinic of pediatric dentistry of the Dental School, University of Athens, for dental restoration. The patient had a BMI of 13.5, which is below the 5th percentile for boys of that age. Medical history included preterm birth with normal karyotype (46 XY). Medical history included asthma controlled with medication and history of pneumonia at the age of 9 months. The child had been hospitalized several times for viral infections and surgical procedures (eg, hypospadias, cryptorchism, and hydrocele). The main medical condition was congenital hyperplasia of adrenal cortex, treated with systematic intake of hydrocortisone $\left(9 \mathrm{mg} / \mathrm{m}^{2}\right.$ 
per day) and potassium levothyroxine (T4, $5 \mu \mathrm{g} / \mathrm{kg}$ ) daily. Dental history included uncooperative behavior with the dentist, toothbrushing once a day by the mother, and severe bruxism during the day and night.

Clinical examination revealed the presence of worn primary dentition and absence of the maxillary primary incisors. Parents reported extraction of the upper incisors due to abscess caused by pulp exposure after severe attrition. Patient had no signs of caries or enamel hypomineralization.

The treatment plan included an individualized preventive program and rehabilitation of dentition with stainless steel crowns applied under general anesthesia (GA). Dental treatment under GA was a necessity not only because the child was uncooperative but also because patients with $\mathrm{CAH}$ need administration of supplemental doses of glucocorticoids to cope with dental anxiety.

Before the scheduled appointment for dental treatment under GA, the patient presented for emergency care because of gingival swelling, halitosis, and abnormal mobility of first upper primary molars. The patient received a triple daily dose of supplemental steroids, and the teeth were extracted under local anesthesia. In addition, abnormal mobility of the primary lower left central incisor was recorded, and radiographic examination revealed severe bone loss (Fig 1). The incisor fell off during the examination. All teeth were sent for histologic examination to define the cause of the multiple tooth loss, and laboratory blood tests were requested.

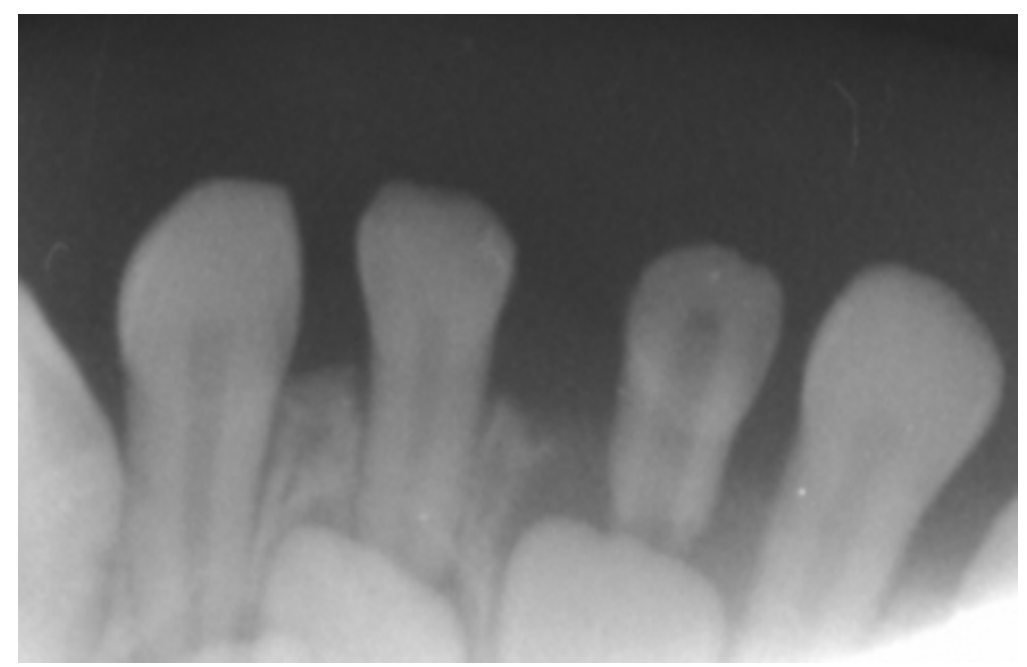

FIGURE 1 Periapical radiograph of the lower anterior teeth, revealing severe bone loss around the lower left central incisor and accelerated eruption of its successor. 
Regarding premature exfoliation of primary teeth, the patient was checked for aggressive periodontitis, immunodeficiency (neutropenia, leukocyte adhesion deficiency, leukemia), hypophosphatasia, Langerhans histocytosis, Papillon-Lefèvre syndrome, diabetes mellitus, hyperthyroidism, dentinal dysplasia, acatalasia, Singleton-Merten syndrome, Hajdu-Cheney syndrome, Coffin-Lowry syndrome, and Chediak-Higashi syndrome.

Histologic examination of the teeth revealed normal tooth structure (Fig 2). Hematologic examination showed periodic alteration of alkaline phosphatase and normal blood values. Plaque test results showed a pattern of colonization relevant to the patient's age. Aggregatibacter actinomycetemcomitans was not detected. These findings were inconclusive for a final diagnosis of the conditions and syndromes mentioned earlier.

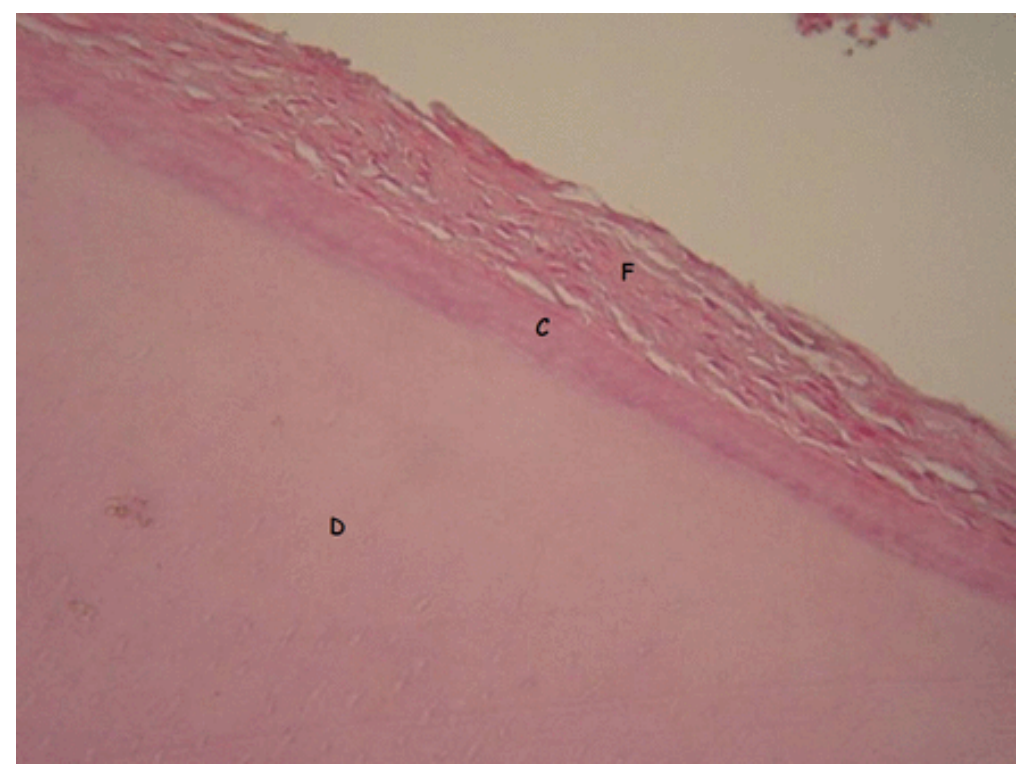

FIGURE 2 Histologic examination of lower left central incisor, revealing normal tooth structure. Different tissues are marked with letters: C, cementum; D, dentine; F, periodontal fibers.

At the scheduled appointment for dental treatment under GA, periodontal examination revealed mild gingival inflammation and plaque accumulation but no attachment loss. Permanent rehabilitation of the patient was performed (Fig 3 ), followed by tooth cleaning and fluoride treatment. As shown in Fig 3 , all teeth had normal enamel structure. A panoramic radiograph was acquired to evaluate bone structure (Fig 4 ). Through clinical and radiographic evaluation, vertical bone loss and accelerated dental development were observed. More specifically, the first permanent lower right molar, which normally erupts at 6 years old, and the first upper left premolar, which normally erupts at 11 years old, were erupting at the age of 4.5 years. 
NOT THE PUBLISHED VERSION; this is the author's final, peer-reviewed manuscript. The published version may be accessed by following the link in the citation at the bottom of the page.
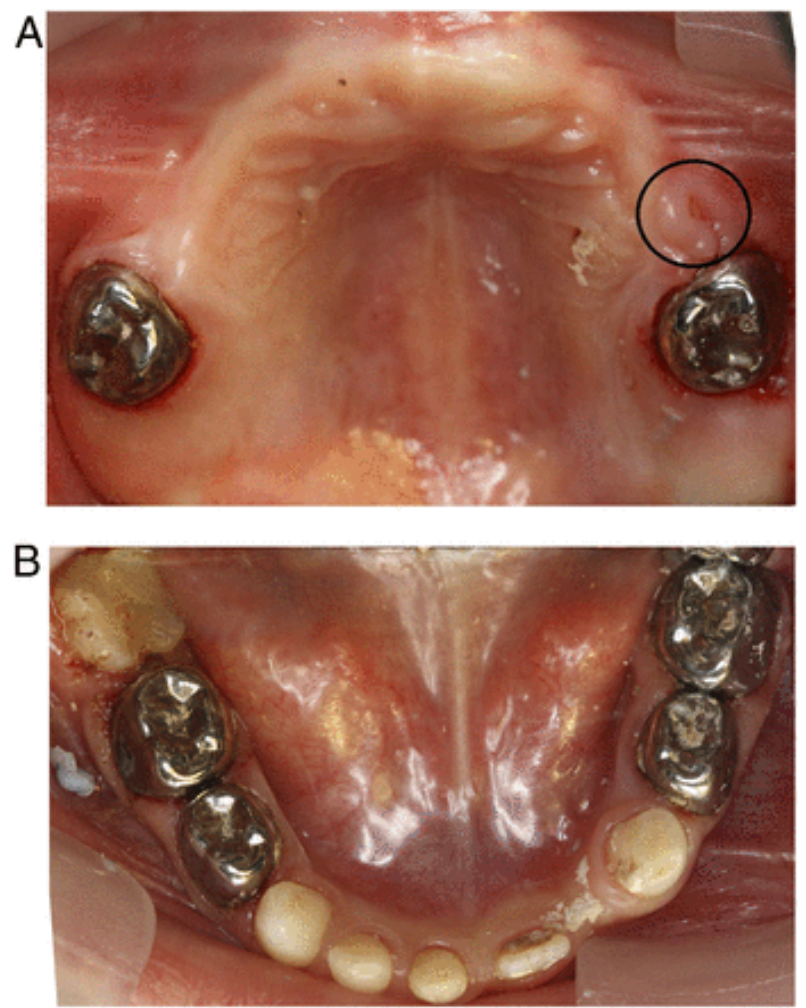

FIGURE 3 Clinical examination of upper (A) and lower (B) arch after rehabilitation under general anesthesia. The left permanent central incisor and the right permanent first molar are present in the mandible. The left second premolar has started erupting in the upper jaw (shown in circle).

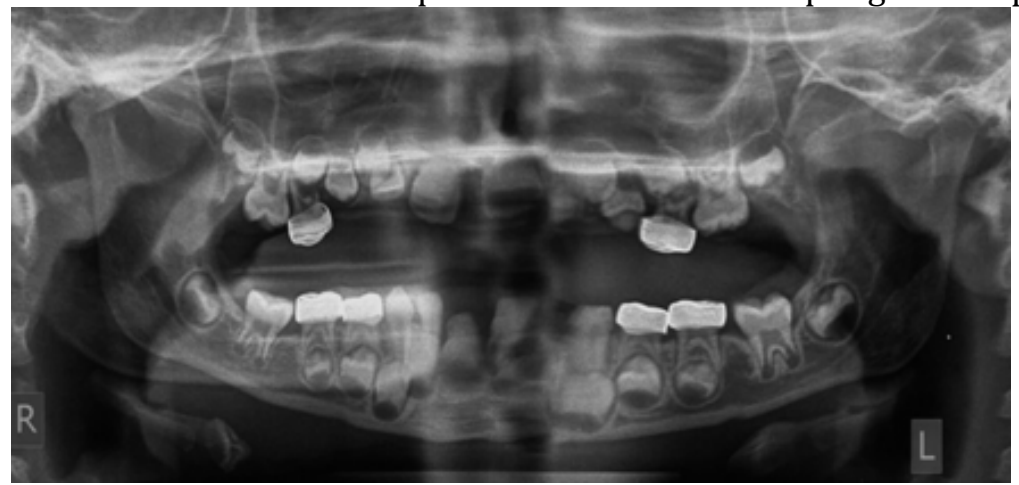

FIGURE 4 Panoramic radiograph at the age of 4.5 years. Severe bone destruction is seen in the upper jaw and the lower anterior zone. Accelerated eruption of permanent teeth is apparent.

At 1-year follow-up, the permanent teeth that had erupted showed class 1 mobility. The anterior teeth were vital, and no inflammation was observed in the gingival tissues. Radiographic examination revealed excessive bone destruction in the anterior region (Fig $\underline{5})$, and eruption of permanent upper and lower central incisors, first molars, and upper premolars at the age of 5.5 years was also recorded ( $\underline{\text { Fig } 6})$. A blood test for bone metabolism markers revealed an elevated RANKL serum level (1459 pg/mL vs RANKL 
normal values of 983-1207 pg/mL) and a lower-than-normal OPG serum level (3213 $\mathrm{pg} / \mathrm{mL}$ vs OPG normal values of 3996-5808 pg/mL). Vitamin D deficiency was also apparent. The patient's genome was checked for RANK mutations, but no findings were reported.

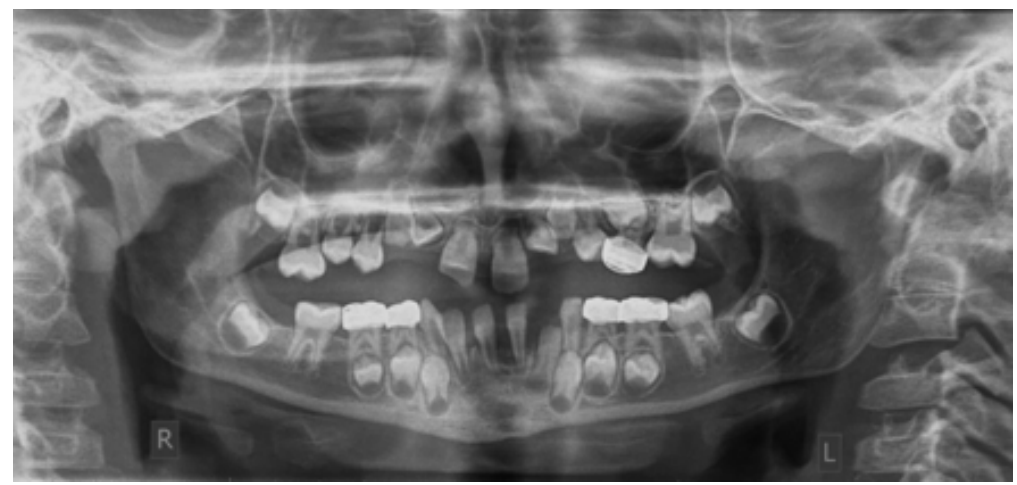

FIGURE 5 Panoramic radiograph at the age of 5.5 years. Severe bone destruction is seen in the upper jaw and the lower anterior teeth. Erupted permanent teeth have immature apices.

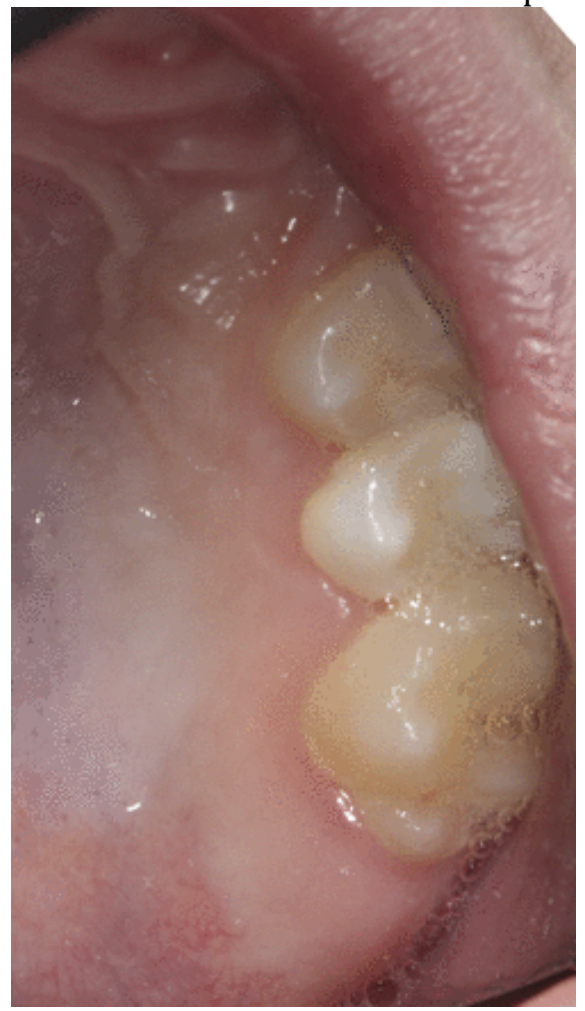

FIGURE 6 Clinical examination of the maxilla at the age of 5.5 years. Left permanent molars and premolars are seen.

After consultation with the endocrinologist, the child was treated with $25(\mathrm{OH})$ vitamin $\mathrm{D}_{3}$ supplements daily (30 $\mathrm{ng} / \mathrm{mL}$ ) for 6 months, and the tooth mobility has been 
NOT THE PUBLISHED VERSION; this is the author's final, peer-reviewed manuscript. The published version may be accessed by following the link in the citation at the bottom of the page.

absent ever since. The patient is monitored by the endocrinologist to avoid future bone destruction.

\section{Discussion}

This report suggests that early exfoliation of primary teeth can be a side effect of bone resorption in patients with CAH. Early exfoliation of the primary dentition and bone loss is an uncommon finding in children. However, whenever it occurs is important to diagnose the patient early because it is usually correlated with serious systematic diseases. $\underline{18}$

Premature loss of primary teeth has not been reported in the past in a case of CAH. However, CAH should be included in the differential diagnosis of premature loss of teeth because disturbance in dental development may be the first symptom of this disorder. 13 Other systematic diseases that may cause premature exfoliation of teeth include hypophosphatasia, aggressive periodontitis, Papillon-Lefèvre syndrome, Singleton-Merten syndrome, Hajdu-Cheney syndrome immunodeficiency (neutropenia, leukocyte adhesion deficiency, leukemia), Langerhans histocytosis, diabetes mellitus, hyperthyroidism, cherubism, dentinal dysplasia, Ehlers-Danlos syndrome, Coffin-Lowry syndrome, ChediakHigashi syndrome, acatalasia, acrodynia, mucocutaneous dyskeratosis, and erythromelalgia. $\underline{18}-\underline{20}$

Hypophosphatasia, immunodeficiency, diabetes mellitus, hyperthyroidism, and acatalasia can be excluded with hematologic examination. $\underline{18} \underline{21}$ In the present case, blood tests revealed normal blood values in all tested enzymes, hormones, or cell numbers. Langerhans histocytosis, cherubism, and dentinal dysplasia present with bone lesions or dental morphology characteristic for these type of diseases. 18 Acrodynia is usually correlated with mercury poisoning, which was not recorded in the patient's medical history. $\underline{18}$

Papillon-Lefèvre syndrome, Ehlers-Danlos syndrome, mucocutaneous dyskeratosis, and erythromelalgia present specific dermatologic findings that were absent in the present patient. $\underline{19}, \underline{20}, \underline{22}, \underline{23}$

Children with Coffin-Lowry syndrome have mental retardation, distinguishing facial characteristics, and skeletal abnormalities that were not present in this child. $\underline{\underline{24}}$ Moreover, none of the clinical features of Chediak-Higashi syndrome, such as albinism, strabismus, and nystagmus, infections of the skin and respiratory tract, and characteristic alterations in 
blood cell values and cell morphology, were found in the present patient. $\underline{25}$ Patients with Singleton-Merten syndrome usually present with skeletal and joint defects, glaucoma, and calcification of the aortic arch, whereas Hajdu-Cheney syndrome is characterized by joint problems and multiple osteolytic lesions. 18 None of these defects were apparent in this patient.

Aggressive periodontitis is a rare condition characterized by rapid loss of periodontal attachment and destruction of the bone. 26 Usually the patients have an unrevealing medical history and present with minor inflammation of gingival tissues and minimal plaque accumulation that is incompatible with the severity of periodontal damage. $\underline{26}$ Sometimes high levels of $A$. actinomycetemcomitans are detected. .26 In the present patient, $A$. actinomycetemcomitans was not detected in the plaque microflora. The patient presented with bone destruction and gingival inflammation, but loss of attachment was not observed. However, attachment loss measurement cannot be clinically reliable in children because of continuous growth and tooth eruption. $\underline{27}$

The present case reported a child with severe bruxism. Current literature suggests a prevalence of $5.9 \%$ to $49.6 \%$ of bruxism in children. $\underline{28}$ However, tooth loss due to bruxism has not been reported in the literature in either children or adults despite the high prevalence of bruxism.

Bone destruction has been correlated with adrenal gland hormone alterations. $\underline{7}$ Usually children with CAH present with accelerated bone growth caused by androgen overproduction. ${ }^{\mathbb{7}}$ However, osteoclastogenesis has also been reported in these children as a side effect of long-term glucocorticoid therapy. $\underline{6} \underline{29}$ This might have caused the bone destruction in this patient. In addition, osteoclastogenic activity can be monitored by testing the RANKL and OPG levels in the patient's serum. 17 In patients with CAH, RANKL levels are elevated whereas OPG levels are lower than normal. 6 The findings in the present case report are consistent with the literature and suggest that patient had elevated osteoclastic activity. For this reason, the endocrinologist suggested a serum test for vitamin $\mathrm{D}$, which was found to be lower than normal, and the patient was given supplements to increase bone density.

Other conditions presenting with bone destruction have been reported in the literature. $\underline{30}$ In particular, familial expansive osteolysis and Paget disease of the bone have been related to mutations in the gene responsible for receptor activator of nuclear factor$\kappa \mathrm{B}(\mathrm{RANK}) . \underline{31}$ However, in the present case no RANK mutations were detected in the genome.

Pediatrics, Vol. 135, No. 6 (June 2015): pg. e1524-e1529. DOI. This article is (C American Academy of Pediatrics and permission has been granted for this version to appear in e-Publications@Marquette. American Academy of Pediatrics does not grant permission for this article to be further copied/distributed or hosted elsewhere without the express permission from American Academy of Pediatrics. 
Moreover, RANKL levels have been correlated with disturbances in tooth eruption. $\underline{17}$ Accelerated development has been reported in children with $\mathrm{CAH}, \underline{12}-\underline{15}$ as was observed for this patient. Accelerated eruption of permanent teeth may have been caused by corticosteroid- or androgen-induced bone destruction $\underline{14}-16$ and can be a sign of bone metabolism disturbances. However, premature exfoliation in the present case may have been a side effect of accelerated eruption of permanent teeth.

Additional case-control studies will be needed to define the correlation of premature exfoliation and bone resorption in patients with $\mathrm{CAH}$.

\section{Acknowledgments}

The authors thank the Department of Experimental Surgery and Surgical Research, Medical School, University of Athens, Greece, assistant professor Apostolos Tsolakis, and Dr Yannis Lyros for conducting the RANKL and OPG tests. Also, we thank assistant professor Christina Kanaka for the medical records and follow-up of the patient.

\section{Footnotes}

- $\quad$ Address correspondence to Matina Angelopoulou, 415 East Vine St \#304, Milwaukee, WI 53212. E-mail: matinangelop@yahoo.gr

- Matina V. Angelopoulou treated the patient and drafted the initial manuscript; Elias Kontogiorgos analyzed the RANKL and osteoprotegerin levels and edited the manuscript; Dimitris Emmanouil designed the treatment plan for the patient, supervised the treatment and follow-up, and edited the manuscript; and all authors approved the final manuscript as submitted.

- FINANCIAL DISCLOSURE: The authors have indicated they have no financial relationships relevant to this article to disclose.

- FUNDING: RANKL and osteoprotegerin tests were conducted at the Department of Experimental Surgery and Surgical Research, Medical School, University of Athens, Greece with supplies provided by the department.

- POTENTIAL CONFLICT OF INTEREST: The authors have indicated they have no potential conflicts of interest to disclose.

\section{References}

${ }^{1}$ Carlson AD, Obeid JS, Kanellopoulou N, Wilson RC, New MI . Congenital adrenal hyperplasia: update on prenatal diagnosis and treatment. J Steroid Biochem Mol Biol. 1999;69(1-6):19-29

${ }^{2}$ Charmandari E, Brook CG, Hindmarsh PC . Classic congenital adrenal hyperplasia and puberty. EurJ Endocrinol. 2004;151(suppl 3):U77-U82

${ }^{3}$ Merke DP, Bornstein SR . Congenital adrenal hyperplasia. Lancet. 2005;365(9477):2125-2136

Pediatrics, Vol. 135, No. 6 (June 2015): pg. e1524-e1529. DOI. This article is C American Academy of Pediatrics and permission has been granted for this version to appear in e-Publications@Marquette. American Academy of Pediatrics does not grant permission for this article to be further copied/distributed or hosted elsewhere without the express permission from American Academy of Pediatrics. 
NOT THE PUBLISHED VERSION; this is the author's final, peer-reviewed manuscript. The published version may be accessed by following the link in the citation at the bottom of the page.

${ }^{4}$ Klingensmith GJ, Garcia SC, Jones HW, Migeon CJ, Blizzard RM . Glucocorticoid treatment of girls with congenital adrenal hyperplasia: effects on height, sexual maturation, and fertility. J Pediatr. 1977;90(6):996-1004

${ }^{5}$ Liu D, Ahmet A, Ward L, et al. . A practical guide to the monitoring and management of the complications of systemic corticosteroid therapy. Allergy Asthma Clin Immunol. 2013;9(1):30

6Faienza MF, Brunetti G, Colucci S, et al. . Osteoclastogenesis in children with 21-hydroxylase deficiency on long-term glucocorticoid therapy: the role of receptor activator of nuclear factor-kappaB ligand/osteoprotegerin imbalance. J Clin Endocrinol Metab. 2009;94(7):2269-2276

${ }^{7}$ Hardy R, Cooper MS. Adrenal gland and bone. Arch Biochem Biophys. 2010;503(1):137-145

${ }^{8}$ Mitchell DR, Lyles KW. Glucocorticoid-induced osteoporosis: mechanisms for bone loss; evaluation of strategies for prevention. J Gerontol. 1990;45(5):M153-M158

${ }^{9}$ Ramírez F, Fowell DJ, Puklavec M, Simmonds S, Mason D. Glucocorticoids promote a TH2 cytokine response by CD4+ T cells in vitro. J Immunol. 1996;156(7):2406-2412

${ }^{10}$ Breivik T, Opstad PK, Gjermo P, Thrane PS. Effects of hypothalamic-pituitary-adrenal axis reactivity on periodontal tissue destruction in rats. Eur J Oral Sci. 2000;108(2):115-122

${ }^{11}$ Matthews DC, Smith CG, Hanscom SL. Tooth loss in periodontal patients. J Can Dent Assoc. 2001;67(4):207-210

${ }^{12}$ Hallett KB, Hall RK. Congenital adrenal hyperplasia and enamel hypoplasia: case report. Pediatr Dent. 1995;17(1):54-59

13Singer S, Pinhas-Hamiel 0, Botzer E. Accelerated dental development as a presenting symptom of 21hydroxylase deficient nonclassic congenital adrenal hyperplasia. Clin Pediatr (Phila). 2001;40(11):621-623

${ }^{14}$ Wagner R, Cohen MM, Hunt EE Jr. Dental development in idiopathic sexual precocity, congenital adrenocortical hyperplasia, and adrenogenic virilism. J Pediatr. 1963;63:566-576

${ }^{15}$ Bergstrand CG, Filipsson R. Dental development in congenital adrenal hyperplasia. Acta Paediatr Scand. 1967;56(suppl 177):78-79

16Burn-Murdoch RA. The effect of corticosteroids and cyclophosphamide on the eruption of resected incisor teeth in the rat. Arch Oral Biol. 1988;33(9):661-667

${ }^{17}$ Castaneda B, Simon Y, Jacques J, et al. Bone resorption control of tooth eruption and root morphogenesis: Involvement of the receptor activator of NF- $\mathrm{KB}$ (RANK). J Cell Physiol. 2011;226(1):74-85

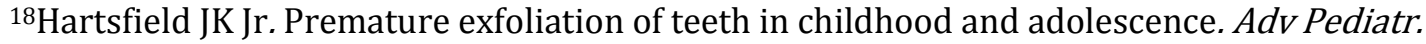
1994;41:453-470

${ }^{19}$ Agostini M, Valiati R, León JE, Romañach MJ, Scully C, de Almeida OP. Mucocutaneous dyskeratosis with periodontal destruction and premature tooth loss. Oral Surg Oral Med Oral Pathol Oral Radiol. 2012;113(2):254-259

${ }^{20}$ Prabhu N, Alexander S, Wong P, Cameron A. Erythromelalgia presenting with premature exfoliation of primary teeth: a diagnostic dilemma. Pediatr Dent. 2012;34(5):422-426

${ }^{21}$ Hollis A, Arundel P, High A, Balmer R. Current concepts in hypophosphatasia: case report and literature review. Int J Paediatr Dent. 2013;23(3):153-159

22Dhanrajani PJ. Papillon-Lefevre syndrome: clinical presentation and a brief review. Oral Surg Oral Med Oral Pathol Oral Radiol Endod. 2009;108(1):e1-e7

Pediatrics, Vol. 135, No. 6 (June 2015): pg. e1524-e1529. DOI. This article is (C) American Academy of Pediatrics and permission has been granted for this version to appear in e-Publications@Marquette. American Academy of Pediatrics does not grant permission for this article to be further copied/distributed or hosted elsewhere without the express permission from American Academy of Pediatrics. 
${ }^{23}$ Abel MD, Carrasco LR. Ehlers-Danlos syndrome: classifications, oral manifestations, and dental considerations. Oral Surg Oral Med Oral Pathol Oral Radiol Endod. 2006;102(5):582-590

${ }^{24}$ Norderyd J, Aronsson J. Hypoplastic root cementum and premature loss of primary teeth in CoffinLowry syndrome: a case report. Int J Paediatr Dent. 2012;22(2):154-156

${ }^{25}$ Rezende KM, Canela AH, Ortega AO, Tintel C, Bönecker M. Chediak-Higashi syndrome and premature exfoliation of primary teeth. Braz Dent J. 2013;24(6):667-670

${ }^{26}$ Masamatti SS, Kumar A, Virdi MS. Periodontal diseases in children and adolescents: a clinician's perspective part. Dent Update. 2012;39(8):541-544, 547-548, 551-542

${ }^{27}$ Pierro VS, de Souza IP, Luiz RR. Influence of local factors on cementoenamel junction-alveolar bone crest distance in primary dentition. J Clin Pediatr Dent. 2009;33(3):199-206

${ }^{28}$ Machado E, Dal-Fabbro C, Cunali PA, Kaizer OB. Prevalence of sleep bruxism in children: A systematic review. Dental Press J Orthod. 2014;19(6):54-61

${ }^{29}$ Zimmermann A, Sido PG, Schulze E, et al. Bone mineral density and bone turnover in Romanian children and young adults with classical 21-hydroxylase deficiency are influenced by glucocorticoid replacement therapy. Clin Endocrinol (Oxf). 2009;71(4):477-484

${ }^{30}$ Regezi JA. Odontogenic cysts, odontogenic tumors, fibroosseous, and giant cell lesions of the jaws. Mod Pathol. 2002;15(3):331-341

31Whyte MP. Paget's disease of bone and genetic disorders of RANKL/OPG/RANK/NF-kappaB signaling. Ann N Y Acad Sci. 2006;1068:143-164 